\title{
Age and Growth of the Cardinalfish Apogon lineatus in Tokyo Bay, Japan
}

\author{
Gen Kume, Atsuko Yamaguchi, and Toru Taniuchi \\ Department of Aquatic Bioscience, Graduate School of Agricultural and Life science, \\ The University of Tokyo, Yayoi, Bunkyo, Tokyo 113-8657, Japan
}

(Received April 24, 1998)

Age and growth of the cardinal fish Apogon lineatus in Tokyo Bay were estimated from right sagittal otoliths of 556 fish. Examination of the outer margins of the otoliths showed that the translucent zone was formed once a year, and can be used as an annulus, with its formation completed at the beginning of the spawning season. Growth of fish, expressed by the von Bertalanffy growth equation, was $L_{t}$ $=86.6[1-\exp \{-1.12(t+0.01)\}]$ for males, and $L_{t}=118.5[1-\exp \{-0.37(t+1.03)\}]$ for females, where $L_{t}$ is total length in $\mathrm{mm}$ and $t$ is age in years. Growth of males and females differed. Females were larger than males at each estimated age. Most fish examined were ages 1 and 2, although the oldest fish were 3 years old for both sexes.

Key words: Tokyo Bay, Apogon lineatus, age and growth, otolith

The cardinal fish Apogon lineatus inhabits sandy or muddy bottoms from coastal inlet to a depth of $100 \mathrm{~m}$, from Uchiura Bay in Hokkaido, Japan to the South China Sea and the Indo-West Pacific. ${ }^{1)}$ In Tokyo Bay, this species is one of the major components of the fish fauna, ${ }^{2)}$ and many are taken as bycatch in bottom trawl fisheries which target mantis shrimp, mud dab and conger eel.

This species is well known for the peculiar habit of mouthbrooding by males. There is, however, insufficient information available on the life history of the species, because it is rarely targeted by commercial fisheries. The only studies on age and growth of $A$. lineatus are by Omori and Takahashi, ${ }^{3)}$ and Yamada, ${ }^{4}$ who analyzed monthly changes in body length. In this study, we attempted to clarify age and growth of $A$. lineatus in Tokyo Bay using otoliths.

\section{Materials and Methods}

Fish were collected from May 1996 to February 1998 by commercial bottom trawling in Tokyo Bay. A map of the study site, and description of fishing gear were given by Yamaguchi et al..$^{5)}$ A total of 564 specimens (male $=260$, female $=304$ ) were examined. Most of the collected specimens were kept frozen for later measurements, while some were immediately measured after we returned to the laboratory. Total length of fish was measured to the nearest $\mathrm{mm}$. Size distribution of the collected specimens was showed in Table 1.

Sagittal otoliths were removed from specimens and kept in glass vials. Some of the otoliths, especially the larger ones, were ground with a whetstone until the focus could be seen clearly. The otoliths were placed in a watch glass containing glycerine. They were examined with a binocular microscope using transmitted and reflected light against a black background, and the otolith radius and ring radii were measured to $0.01 \mathrm{~mm}$ with a built-in measuring device. The otolith radius and ring radii were measured from focus to the posterior distal margin of the
Table 1. Size distribution of specimens

\begin{tabular}{crcc}
\hline \hline \multirow{2}{*}{$\begin{array}{c}\text { Total length } \\
(\mathrm{mm})\end{array}$} & \multicolumn{3}{c}{ Number of specimens } \\
\cline { 2 - 4 } & male & female & Total \\
\hline $31-40$ & 1 & 0 & 1 \\
$41-50$ & 3 & 3 & 6 \\
$51-60$ & 20 & 8 & 28 \\
$61-70$ & 37 & 23 & 60 \\
$71-80$ & 90 & 68 & 158 \\
$81-90$ & 68 & 134 & 202 \\
$91-100$ & 38 & 56 & 94 \\
$101-110$ & 3 & 10 & 13 \\
$111-120$ & 0 & 2 & 2 \\
\hline Total & 260 & 304 & 564 \\
\hline
\end{tabular}

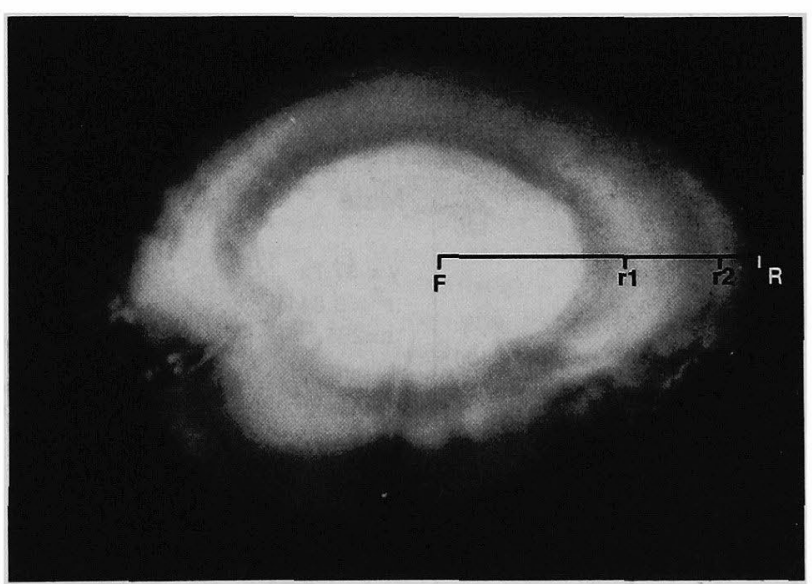

Fig. 1. Otolith of Apogon lineatus, male, $85 \mathrm{~mm}$ in total length collected in July.

$R$, otolith radius $(223 \mathrm{~mm})$; r1-r2, annual ring radii $1-2 ; F$, focus.

otolith, and to the outer margins of the translucent zones, respectively. (Fig. 1). Since there were no differences in size and ring formation between right and left otoliths, 
only right otoliths were used for measurements.

The period of annulus formation was determined by monthly changes in percentage occurrence of otoliths with opaque margins. The von Bertalanffy growth equation was estimated using Akamine's program ${ }^{6)}$ which implements Marquardt's algorithm for nonlinear least squares parameter estimation.

\section{Results}

Of 564 otoliths examined $556(98.6 \%)$ were readable, the remaining 8 otoliths had obscure rings. Monthly changes in percentage occurrence of otoliths with an opaque margin are shown in Fig. 2. The formation of the translucent zone began in August and was completed between March and June. The completion of the period of translucent zone formation coincides with the beginning of the spawning season of $A$. lineatus in Tokyo Bay. These data indicate that the translucent zone is formed once a year and it can be used as an annual mark (annulus) for age determination.

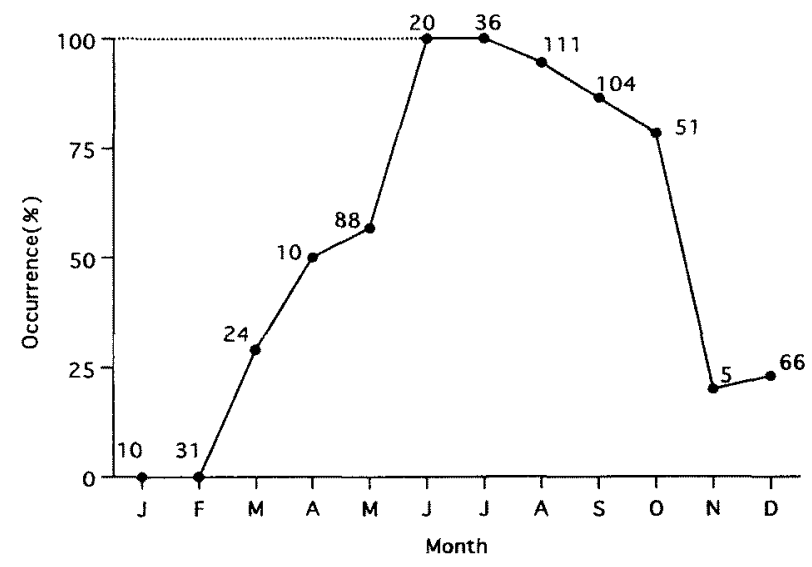

Fig. 2. Monthly changes in percentage occurrence of otoliths with an opaque margin in Apogon lineatus.

Numbers represent total number of ototiths read each month.
The relationships between otolith radius and total length are shown in Fig. 3. The equations are as follows:

$$
\begin{array}{lll}
\text { male } & T L=37.7 R^{1,000} & \left(r^{2}=0.841, n=255\right), \\
\text { female } & T L=41.9 R^{0.874} & \left(r^{2}=0.804, n=301\right),
\end{array}
$$

where $T L$ is total length in $\mathrm{mm}$ and $R$ is otolith radius in $\mathrm{mm}$. Because analysis of covariance showed a significant difference between males and females $(P<0.05)$, these data were treated separately for sexes. The mean radii of each successive otolith ring at each estimated age for males and females are shown in Table 2. These data show Lee's phenomenon, the mean radius of each ring decreasing with age, in both sexes. Therefore, following Uehara and Shimizu, ${ }^{7}$ we used the mean radii of the most recent ring at each estimated age for back-calculating fish length ( $\mathrm{Ta}$ ble 2).

The von Bertalanffy growth equations derived from the back-calculated length were as follows:

Table 2. Mean otolith ring radii $( \pm S D)$ at estimated age for males

\begin{tabular}{|c|c|c|c|c|}
\hline \multirow{2}{*}{ Estimated age (year) } & \multirow{2}{*}{$N$} & \multicolumn{3}{|c|}{$\begin{array}{c}\text { Male } \\
\text { Mean otolith ring radii (mm) }\end{array}$} \\
\hline & & $r 1$ & $\mathrm{r} 2$ & r3 \\
\hline 1 & 165 & $1.56 \pm 0.21$ & & \\
\hline 2 & 65 & $1.45 \pm 0.16$ & $2.06 \pm 0.18$ & \\
\hline 3 & 8 & $1.26 \pm 0.06$ & $1.84 \pm 0.14$ & $2.22 \pm 0.11$ \\
\hline $\begin{array}{l}\text { Back-calculated } \\
\text { total length }(\mathrm{mm})\end{array}$ & & 58.8 & 77.6 & 83.7 \\
\hline \multirow[t]{2}{*}{ Estimated age (year) } & \multirow[t]{2}{*}{$N$} & \multicolumn{3}{|c|}{$\begin{array}{c}\text { Female } \\
\text { Mean otolith ring radii (mm) }\end{array}$} \\
\hline & & $\mathrm{r} 1$ & $\mathrm{r} 2$ & r3 \\
\hline 1 & 180 & $1.60 \pm 0.21$ & & \\
\hline 2 & 99 & $1.45 \pm 0.20$ & $2.11 \pm 0.19$ & \\
\hline 3 & 4 & $1.39 \pm 0.20$ & $2.05 \pm 0.16$ & $2.47 \pm 0.12$ \\
\hline $\begin{array}{l}\text { Back-calculated } \\
\text { total length }(\mathrm{mm})\end{array}$ & & 63.1 & 80.4 & 92.3 \\
\hline
\end{tabular}
and females Apogon lineatus
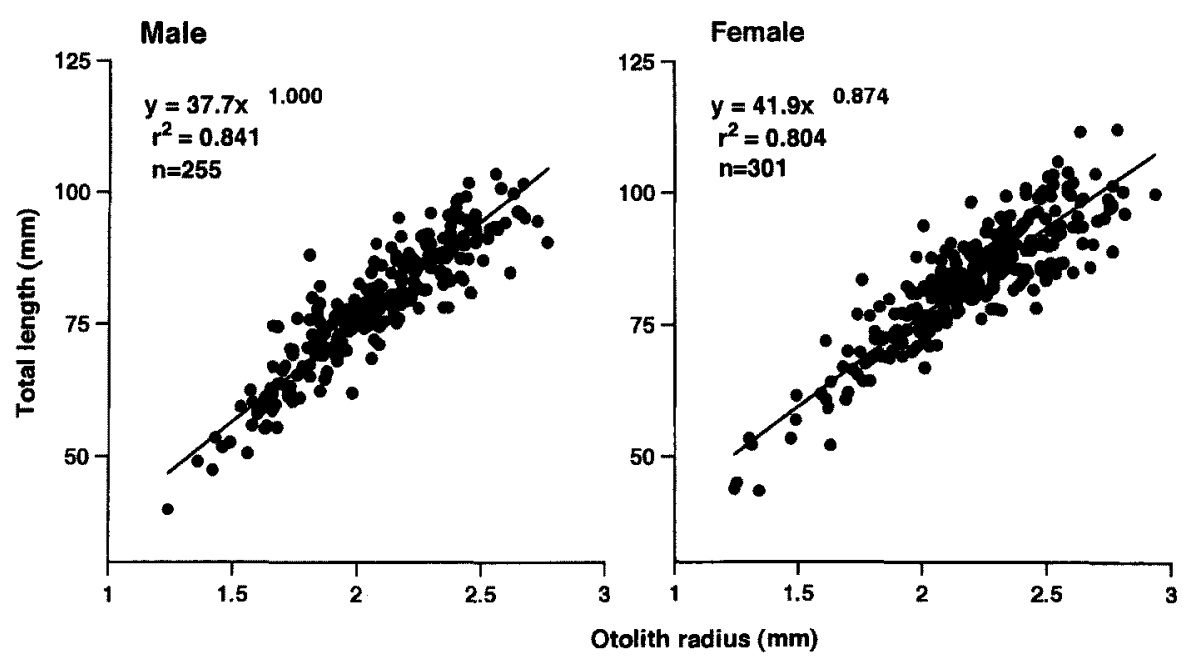

Fig. 3. Relationships between otolith radius (R) and total length (TL) for male and female Apogon lineatus. 


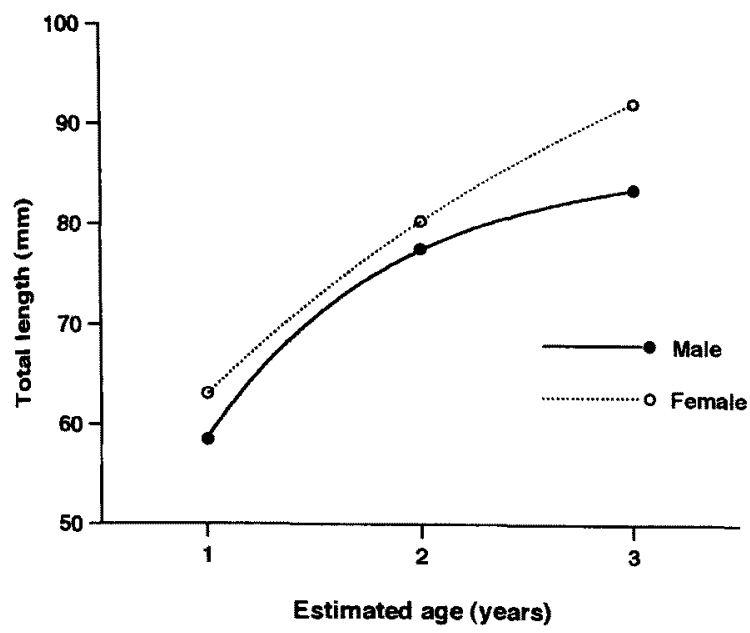

Fig. 4. The von Bertalanffy growth curves for male and female Apogon lineatus.

The closed and opened circles are the back-calculated total length at estimated age for males and females, respectively.

$$
\begin{array}{ll}
\text { male } & L_{t}=86.6[1-\exp \{-1.12(t+0.01)\}], \\
\text { female } & L_{t}=118.5[1-\exp \{-0.37(t+1.03)\}],
\end{array}
$$

where $t$ is age in years and $L_{t}$ is total length in $\mathrm{mm}$ at age $t$. Females are larger than males at each age (Fig. 4).

The maximum age was 3 years old for both sexes. Total length for each age estimated by the von Bertalanffy equation is for males, $58.6 \mathrm{~mm}$ at age $1,77.4 \mathrm{~mm}$ at age $2,83.6$ $\mathrm{mm}$ at age 3 , and for females $62.5 \mathrm{~mm}$ at age $1,79.8 \mathrm{~mm}$ at age $2,91.8 \mathrm{~mm}$ at age 3 . The observed maximum total length was $103 \mathrm{~mm}$ for males and $112 \mathrm{~mm}$ for females.

\section{Discussion}

In this study we used otoliths for aging $A$. lineatus. The boundaries between translucent and opaque zones were clearly defined, and $98.6 \%$ of otliths examined were readable. Few studies have used annual ring readings to examine age and growth of Apogonidae. Suzuki and $\mathrm{Ueno}^{8}$ used scales for aging $A$. cyanosoma in Suruga Bay. We also attempted to use scales for aging $A$. lineatus, but found that scales had obscure annuli and thus were less ageable than otoliths.

Beckman and Wilson ${ }^{97}$ suggested that opaque zones on otoliths of $60-70 \%$ of 94 fish species inhabiting the temperate zone in the Northern Hemisphere (Lat. 23-45 N) are formed between spring and early summer. However, in this study we found that the opaque zone on otoliths of $A$. lineatus was formed during a longer period, from spring to autumn. Beckman and Wilson ${ }^{9}$ also reported on the relationship betwefen breeding seasons and periods of opaque zone formation in otoliths. We also observed that opaque zone of otoliths in A. lineatus was formed almost during the breeding season.

Differences in growth between males and females were evident in our study. Females were larger than males at each estimated age. In Apogonidae males cannot take ordi- nary food during mouthbrooding, ${ }^{10)}$ which may account for the smaller size of males.

We compared our mean back-calculated lengths with Omori and Takahashi data ${ }^{3)}$ for $A$. lineatus from Yuya Bay, Yamaguchi Prefecture. Our length at age 1 was much less than that of fish from Yuya Bay (male: 58.8 vs. 69 mm, female: 63.1 vs. $82 \mathrm{~mm}$ ). The maximum ages of $A$. lineatus from Tokyo Bay were the oldest in the previous studies. Yamada, ${ }^{4)}$ and Omori and Takahashi ${ }^{33}$ reported the maximum age was 2 years old for both sexes. The difference with our values is undoubtedly due to differences in methods of determining age.

Yamaguchi et al. ${ }^{11)}$ in their investigation of geographic variations in growth of the starspotted dogfish Mustelus manazo, found that age and growth of $M$. manazo in Tokyo Bay were different from those of other regions. Tokyo Bay is a closed bay and has peculiar characteristics as compared to the other bays. Differences in age and growth of $A$. lineatus in Tokyo Bay from those of other regions may be caused by a peculiar characteristics in Tokyo Bay (e.g. water temperature and food availability) or the differences in life history of this species, and further study is necessary.

Acknowledgments We are grateful to the commercial fishermen of the Shiba Branch of Yokohama City Fisheries Cooperative Association for their help in sampling. We appreciate Sus Kato for reviewing our manuscript. This study was supported in part by a Grants-in Aid for Scientific Research from the Ministry of Education, Science, Sports and Culture of Japan (09NP0901).

\section{References}

1) T. Nakabo: Fishes of Japan with Pictoral Keys to the Species, Tokai University Press, Tokyo, 1993, p. 676.

2) M. Tokimura: Distribution of Demersal Fishes in Tokyo Bay, $\mathrm{Ph}$ D. thesis, University of Tokyo, Tokyo, 1985, p. 156.

3) M. Omori and K. Takahashi: Ecological studies on the Apogonid Fish Tenjikudai (Apogon lineatus) in Yuya Bay. Bull. Seikai Reg. Fish. Res. Lab., 54, 113-133 (1980) (in Japanese).

4) T. Yamada: Studies on morphometry and bionomics of Indianperch, Apogon lineatus (Temmink et Schlegel) in Omura Bay. Bull. Fac. Fish., Nagasaki Univ., 5, 80-90 (1957) (in Japanese).

5) A. Yamaguchi, T. Taniuchi, and M. Shimizu: Age and growth of the starspotted dogfish Mustelus manazo from Tokyo Bay, Japan. Fisheries Sci., 62, 919-922 (1996).

6) T. Akamine: Expansion of growth curves using a periodic function and BASIC programs by MARquardT's methods. Bull. Jap. Sea Reg. Fish. Res. Lab., 36, 77-107 (1986).

7) S. Uehara and M. Shimizu: Age and growth of stone flounder Kareius bicoloratus in Tokyo Bay, Japan. Fisheries Sci., 62, 897901 (1996).

8) K. Suzuki and S. Ueno: Life history of the cardinalfish, Apogon cyanosoma, in Suruga Bay, Central Japan. Bull. Inst. Oceanic Res. Develop., Tokai Univ., 5, 49-55 (1983) (in Japanese).

9) D. W. Beckman and C. A. Wilson: Seasonal timing of opaque zone formation in fish otoliths, in "Recent Developments in Fish Otolith Research" (ed. by D. H. Secor, J. M. Dean, and S. E. Campana), University of South Carolina Press, 1995, pp. 27-43.

10) T. Kuwamura: Mouthbrooding and marriage form of Apogonidae, in "Breeding Behavior of Fishes" (ed. by A. Goto and K. Maekawa), Tokai University Press, Tokyo, 1989, pp. 140-150.

11) A. Yamaguchi, T. Taniuchi, and M. Shimizu: Geographic variation in growth of the starspotted dogfish Mustelus manazo from five localities in Japan and Taiwan. Fisheries Sci., 64, 732-739 (1998). 